Boston University School of Law Scholarly Commons at Boston University School of Law

Faculty Scholarship

$8-2017$

\title{
Anti-bullying Policies and Disparities in Bullying: A State-Level Analysis
}

\author{
Angela Onwuachi-Willig \\ Boston University School of Law \\ Mark Hatzenbuehler \\ Javier Flores \\ Joesph Cavanaugh
}

Follow this and additional works at: https://scholarship.law.bu.edu/faculty_scholarship

Part of the Juvenile Law Commons

\section{Recommended Citation}

Angela Onwuachi-Willig, Mark Hatzenbuehler, Javier Flores \& Joesph Cavanaugh, Anti-bullying Policies and Disparities in Bullying: A State-Level Analysis, 53 American Journal of Preventative Medicine 184 (2017).

Available at: https://scholarship.law.bu.edu/faculty_scholarship/293 


\title{
American Journal of \\ Preventive Medicine
}

RESEARCH ARTICLE

\section{Anti-bullying Policies and Disparities in Bullying: A State-Level Analysis}

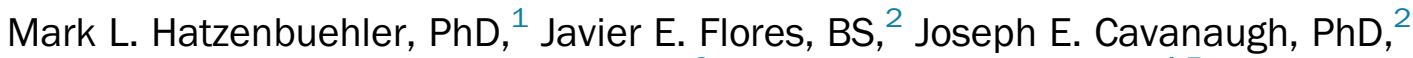 \\ Angela Onwuachi-Willig, JD, ${ }^{3}$ Marizen R. Ramirez, $\mathrm{PhD}^{4,5}$
}

\begin{abstract}
Introduction: Recent research suggests that anti-bullying laws may be effective in reducing risk of bullying victimization among youth, but no research has determined whether these laws are also effective in reducing disparities in bullying. The aim of this paper was to evaluate the effectiveness of anti-bullying legislation in reducing disparities in sex- and weight-based bullying and cyberbullying victimization.
\end{abstract}

Methods: Data on anti-bullying legislation were obtained from the U.S. Department of Education, which commissioned a systematic review of 16 key components of state laws in 2011. States were also categorized based on whether their legislation enumerated protected groups and, if so, which groups were enumerated. These policy variables from 28 states were linked to individual-level data on bullying and cyberbullying victimization from students in 9th through 12th grade participating in the 2011 Youth Risk Behavior Surveillance System study $(\mathrm{N}=79,577)$. Analyses were conducted in 2016.

Results: There was an absence of any kind of moderating effect of anti-bullying legislation on weight-based disparities in bullying and cyberbullying victimization. Only state laws with high compliance to Department of Education enumeration guidelines were associated with lower sexbased disparities in bullying victimization.

Conclusions: Anti-bullying policies were not associated with lower weight-based disparities in bullying and cyberbullying victimization among youth, and only one form of policies (high compliance to Department of Education enumeration guidelines) was associated with lower sexbased disparities in bullying victimization. Results therefore suggest that anti-bullying legislation requires further refinement to protect youth who are vulnerable to bullying victimization.

Am J Prev Med 2017;53(2):184-191. @ 2017 American Journal of Preventive Medicine. Published by Elsevier Inc. All rights reserved.

\section{INTRODUCTION}

$\mathrm{N}$ ationally representative surveys indicate that $15 \%-20 \%$ of high school students report being bullied at school. ${ }^{1}$ Certain groups of youth are at disproportionate risk of being bullied. Overweight/obese youth are significantly more likely than their normalweight peers to experience peer victimization and bullying. ${ }^{2,3}$ Nearly a third of U.S. youth aged 6-19 years are overweight or obese ${ }^{4}$; consequently, weight-based bullying affects a substantial number of youth. In addition, there are sex differences in the types of bullying that youth experience, with girls typically reporting more cyberbullying and more relational bullying than boys. ${ }^{5}$
From the ${ }^{1}$ Department of Sociomedical Sciences, Mailman School of Public Health, Columbia University, New York, New York; ${ }^{2}$ Department of Biostatistics, College of Public Health, University of Iowa, Iowa City, Iowa; ${ }^{3}$ College of Law, University of Iowa, Iowa City, Iowa; ${ }^{4}$ Division of Environmental Health Sciences, School of Public Health, University of Minnesota, Minneapolis, Minnesota; and ${ }^{5}$ University of Iowa Injury Prevention Research Center, College of Public Health, University of Iowa, Iowa City, Iowa

Address correspondence to: Mark L. Hatzenbuehler, PhD, 722 West 168th Street, Room 549B, New York NY 10032. E-mail: mlh2101@cumc. columbia.edu.

0749-3797/\$36.00

https://doi.org/10.1016/j.amepre.2017.02.004 
Because bullying is associated with numerous deleterious outcomes, ${ }^{6}$ reducing group-based differences and disparities in bullying is an important public health priority.

Potential approaches to reducing bullying disparities include anti-bullying policies, schoolwide bullying interventions, and school programs targeted at vulnerable groups (e.g., Gay-Straight Alliances). However, there is scant evidence of the effectiveness of these approaches in reducing disparities in bullying. ${ }^{7}$ Thus, the current study considered the first identified approach-anti-bullying policies-because many schools begin their anti-bullying efforts by adopting a specific policy.

Recent research has begun to evaluate the effectiveness of anti-bullying policies in reducing bullying among youth. One study of more than 60,000 adolescents found that students living in states with at least one U.S. Department of Education (DOE)-recommended legislative component in their anti-bullying law had $24 \%$ lower odds of reporting being bullied and 20\% lower odds of reporting being cyberbullied. ${ }^{8}$ Another study found a slight increase in bullying immediately after Iowa's antibullying law was passed, followed by a decrease 3 years later. ${ }^{9}$ Still, the extent to which anti-bullying laws reduce group-based disparities in bullying is largely unknown. This question was identified as a key research gap in the 2016 National Academy of Sciences report on bullying. ${ }^{7}$

Specific policies targeting groups at risk of bullying, as opposed to general policies that do not enumerate the most vulnerable populations, may be more effective at reducing disparities in bullying. Indeed, some social policies-when they have enumerated and communicated a specific intention to address harms against the stigmatized group-have shown promise in reducing health disparities between stigmatized and nonstigmatized groups. ${ }^{10-12}$ For instance, sexual orientation disparities in psychiatric disorders are significantly lower in states with employment nondiscrimination and hate crime laws that include sexual orientation as protected classes than in states without such laws. ${ }^{10}$ Applied to the bullying context, this research suggests that enumerated anti-bullying legislation may be effective in reducing disparities in bullying, perhaps through providing specific protections to vulnerable youth or creating school climates that promote diversity and inclusion.

On the other hand, whereas enumerated interventions can improve outcomes for protected groups, broad and undefined interventions may simultaneously exacerbate inequalities, a phenomenon known as the inequality paradox. For example, black/white disparities in HIV mortality increased following the introduction of highly active antiretroviral treatment, an effective populationlevel HIV intervention, in part because those with greater access to resources (whites) disproportionately benefited from the treatments. ${ }^{13}$ This research suggests that general (i.e., non-enumerated) anti-bullying policies can be effective at a population level, while at the same time actually widening (or at least not reducing) disparities in bullying. These competing hypotheses were tested by conducting the largest and most comprehensive study to date examining whether anti-bullying legislation is associated with lower levels of disparities in bullying related to sex and weight.

\section{METHODS}

\section{Data Sample}

Data were obtained from the Youth Risk Behavior Surveillance System (YRBSS), which was developed by the Centers for Disease Control and Prevention (CDC) to monitor social issues and health risk behaviors among teenagers in the U.S. Surveys have been conducted every 2 years since 1991 and are based on representative samples of 9th through 12th grade students. These analyses used data from 28 states $(\mathrm{N}=79,577)$ : 25 states were obtained from the 2011 YRBSS combined data sets, and the remaining three (Delaware, Iowa, and South Dakota) were obtained with permission from state public health departments. States were selected on the basis of data availability, response rate ( $\geq 60 \%$ ), and enactment of the state bullying legislation on or prior to January 1, 2011 (which occurred before the anti-bullying legislation was coded, thereby ensuring temporal ordering of the relationship between anti-bullying legislation and bullying disparities). Additional details of YRBSS methods may be accessed elsewhere. ${ }^{14}$ The study was exempted by the IRB because the analyses involved deidentified secondary data analysis.

\section{Measures}

The DOE conducted a comprehensive evaluation of state bullying laws enacted through April 2011. Three policy variables were examined in this study.

First, the DOE categorized bullying legislative and policy provisions according to 11 key components and five subcomponents. ${ }^{15}$ For each, a dichotomous compliance categorization was employed to classify states as compliant if their legislation was at least partially consistent with the DOE recommendation. The scores for each component were summed in order to assign an overall compliance score. Additional details can be found in Hatzenbuehler et al. ${ }^{8}$

Second, one of the DOE components dealt with enumerationthat is, whether the law "conveyed specific protections for individuals with characteristics that may motivate bullying behavior (e.g., disability, sexual orientation, race/ethnicity, or gender)." ${ }^{\prime 15}$ Table 1 presents states according to their compliance with DOE guidelines for enumeration (none, partial, full). No compliance indicates that no groups are enumerated. Partially compliant laws “enumerate victims' characteristics (e.g., sex, race/ethnicity, sexual orientation, weight) but limit coverage to only those protected classes." Florida's partially compliant law, for example, limited coverage to three enumerated groups (sex, religion, and race). Fully compliant laws "do not limit coverage under law to members of those classes (e.g., 'including, but not limited to')." 
Table 1. Department of Education Compliance Score and Enumeration Categorizations for Each State

\begin{tabular}{|c|c|c|c|c|c|}
\hline \multicolumn{3}{|c|}{ Compliance to all DOE guidelines } & \multicolumn{3}{|c|}{ Compliance to DOE enumeration guidelines } \\
\hline Low & Medium & High & None & Partial & Full \\
\hline $\begin{array}{l}\text { Alaska } \\
\text { Idaho } \\
\text { Kansas } \\
\text { Mississippi } \\
\text { Montana } \\
\text { Nebraska } \\
\text { Rhode Island } \\
\text { South Dakota } \\
\text { Wisconsin }\end{array}$ & $\begin{array}{l}\text { Connecticut } \\
\text { Illinois } \\
\text { Kentucky } \\
\text { Louisiana } \\
\text { Maine } \\
\text { New Mexico } \\
\text { Oklahoma } \\
\text { South } \\
\text { Carolina } \\
\text { Tennessee } \\
\text { Virginia } \\
\text { Wyoming }\end{array}$ & $\begin{array}{l}\text { Alabama } \\
\text { Delaware } \\
\text { lowa } \\
\text { Maryland } \\
\text { North Carolina } \\
\text { New Hampshire } \\
\text { Vermont } \\
\text { West Virginia }\end{array}$ & $\begin{array}{l}\text { Alaska } \\
\text { Connecticut } \\
\text { Delaware } \\
\text { Idaho } \\
\text { Kansas } \\
\text { Kentucky } \\
\text { Louisiana } \\
\text { Mississippi } \\
\text { Montana } \\
\text { Nebraska } \\
\text { New Hampshire } \\
\text { Oklahoma } \\
\text { Rhode Island } \\
\text { South Carolina } \\
\text { South Dakota } \\
\text { Tennessee } \\
\text { Virginia } \\
\text { Wisconsin } \\
\text { West Virginia } \\
\text { Wyoming }\end{array}$ & $\begin{array}{l}\text { Alabama } \\
\text { lowa } \\
\text { Vermont }\end{array}$ & $\begin{array}{l}\text { Illinois } \\
\text { Maryland } \\
\text { Maine } \\
\text { North Carolina } \\
\text { New Mexico }\end{array}$ \\
\hline
\end{tabular}

Note: Compliance to all Department of Education (DOE) guidelines is measured with the Total Comprehensive Score (TCS). The TCS ranges from 0 to 16, with a median value of 11 and mean of 10. For compliance to all DOE guidelines, "Low" corresponds to states with a TCS $\leq 9$, "Medium" corresponds to those with $9<$ TCS $\leq 12$, and "High" denotes states with TCS $>12$. Compliance to DOE Enumeration is measured via a DOE-assigned expansiveness score (ES). This score assumes a value of 0 (no compliance), 1 (partial compliance), or 2 (full compliance).

For instance, Illinois' law enumerates several groups but further extends coverage to "any distinguishing characteristic."

Lastly, because the DOE enumeration variable did not specify which groups were enumerated, indicator variables were created respectively for sex and weight based on whether the state enumerated sex or physical appearance/attributes/ weight in their legislation. Table 2 displays the eight states

Table 2. Enumeration of Anti-Bullying Legislation for Sex and Physical Appearance/Weight

\begin{tabular}{|lccc|}
\hline States & $\begin{array}{c}\text { Any } \\
\text { enumeration }\end{array}$ & $\begin{array}{c}\text { Physical appearance } \\
\text { (1), physical } \\
\text { attributes (2), or } \\
\text { weight (3) }\end{array}$ & Sex \\
\hline Alabama & $\checkmark$ & & $\checkmark$ \\
lowa & $\checkmark$ & $\checkmark(2)$ & $\checkmark$ \\
Illinois & $\checkmark$ & $\checkmark(2)$ & $\checkmark$ \\
Maryland & $\checkmark$ & $\checkmark(3)$ & $\checkmark$ \\
Maine & $\checkmark$ & $\checkmark(1)$ & $\checkmark$ \\
North & $\checkmark$ & & $\checkmark$ \\
Carolina & & & $\checkmark$ \\
New & $\checkmark$ & & $\checkmark$ \\
Mexico & & & \\
Vermont & $\checkmark$ & & \\
\hline
\end{tabular}

Note. New Hampshire and Virginia had inconsistent categorization based on two sources (written DOE report and stopbullying.gov website). A law student under the supervision of AOW reviewed New Hampshire and Virginia's laws to determine enumeration coverage.

AOW, Angela Onwuachi-Willig; DOE, Department of Education. that enumerated any protected groups and indicates whether the disparity groups of interest were specifically enumerated in the legislation.

Participants were asked the following questions: During the past 12 months, (1) have you ever been bullied on school property?; and (2) have you ever been electronically bullied? (through email, chat rooms, instant messaging, Web sites, or texting). Prior to these questions, a definition of bullying was provided. ${ }^{14}$ Response options were coded dichotomously, and a student was categorized as reporting being bullied or cyberbullied if they answered positively (hereafter referred to as being "bullied" or "cyberbullied"). Bullying data from 2011 were used because data on antibullying legislation were only available for that year. Using more recent bullying data was problematic because some laws changed after 2011.

Group identification for weight was ascertained in two ways. First, BMI was calculated and assigned to participants based on their self-reported heights and weights. BMIs were dichotomized into high BMI $(\geq 30)$ and low BMI $(<30)$ based on CDC-defined cut points. Second, participants were asked: How do you describe your weight? Those who perceived themselves as very overweight were the high-risk group, whereas those who perceived themselves as very underweight, slightly underweight, about the right weight, and slightly overweight were the reference group. Alternative categorization schemes (e.g., comparing underweight to all other categories) for both measures were explored, and consistent results were obtained (i.e., direction and magnitude of all associations remained unchanged). Both BMI and perceived weight were examined because they are independently associated with adverse outcomes. ${ }^{16}$ For sex, female students were considered the highrisk group. 
The first state-level covariate was violent crime rates and was chosen because higher rates of violent crime may reflect state-level differences in the acceptance of violence, including bullying. The Uniform Crime Reporting Statistics system provides estimates of violent crime rates (murder and non-negligent manslaughter, forcible rape, robbery, and aggravated assault) in each state in 2011 and is measured as the number of violent crimes per 100,000 inhabitants. ${ }^{17}$ The second state-level covariate was "cultural tightness," which refers to the strength of punishment and latitude/ permissiveness of individual deviance, ${ }^{18}$ and was chosen because states with greater cultural tightness were more likely to implement more-comprehensive anti-bullying policies. The measure of cultural tightness includes nine items (e.g., legality of corporal punishment in schools, severity of punishment for violating laws). ${ }^{18}$ In addition to these state-level covariates, each analysis adjusted for demographic characteristics associated with bullying victimization, including age, race, and sex (for analyses on weightbased disparities). These variables were identified either as confounding variables in a Directed Acyclic Graph ${ }^{19}$ in prior research ${ }^{8}$ or as risk factors for bullying whose addition explained variability in the outcome and improved model fit.

\section{Statistical Analysis}

First, multivariable logistic regression was used to investigate disparities in bullying and cyberbullying by sex, BMI, and perceived weight. To compare the odds of being bullied and cyberbullied by sex, BMI, and perceived weight, AORs and their corresponding $95 \%$ CIs were obtained. For example, an OR of 1 comparing male and female students would suggest that there are no bullying disparities by sex. All ORs were adjusted for the stateand individual-level covariates described above.

Second, to test whether living in a state with high compliance to DOE guidelines was associated with lower bullying disparities, models were constructed with interactions between the DOE compliance scores and at-risk groups (i.e., compliance score $\mathrm{X}$ sex, compliance score $\mathrm{X}$ BMI, compliance score $\mathrm{X}$ perceived weight). For these models, AORs for bullying and cyberbullying comparing groups (sex, BMI, and perceived weight categories) were estimated across three levels of the anti-bullying legislation compliance variable: low, medium, and high. These three groups were determined using univariate statistics to obtain the tertiles of the overall compliance scores.

Evidence for effect measure modification would indicate that the sex- or weight-based disparity in being bullied or cyberbullied was lower in states whose anti-bullying legislation was more compliant with DOE recommendations. For instance, if there was evidence for moderation, the AOR for the relationship between sex and being bullied should be the furthest from one in the low compliance category and the closest to one in the high compliance category. To test this empirically, the authors estimated the changes in ORs among the three levels by calculating ratios of ORs (RORs), which characterize the change in ORs from one categorization level to another. In comparing states with high versus low compliance, an ROR $<1$ would indicate that improved compliance is associated with a lower disparity (measured by the $\mathrm{OR})$, an $\mathrm{ROR}=1$ suggests no improvement in the disparity, and ROR $>1$ suggests that the disparity is higher. A failure of the ROR to meet significance indicates that changes in DOE compliance score have no statistically significant effect on the odds of being bullied or cyberbullied. Statistical significance of the RORs (and AORs) was determined via Wald tests.

Third, to examine whether sex- or weight-based disparities in bullying victimization were lower in states that enumerated specific groups, the same procedures were employed. Multivariable logistic models with interactions were constructed to determine whether enumeration of specific groups (enumerated versus not enumerated) by the state anti-bullying laws (Table 2) was associated with sex or weight disparities. The RORs were also examined to assess the protective effects of enumeration.

All models accounted for the hierarchically nested nature of the data by accommodating clustering at the levels of primary sampling unit and state. Sensitivity analyses were conducted with alternative approaches for handling clustered data (i.e., generalized estimating equations and likelihood-based methods for generalized linear mixed models), and the direction and magnitude of the results remained unchanged. Data were weighted according to the weights provided by the YRBSS data set. Analyses were conducted using the SURVEYLOGISTIC procedure in SAS, version 9.4. Analyses were conducted in 2016.

\section{RESULTS}

Evidence of bullying/cyberbullying disparities is provided in Table 3. Girls $(\mathrm{AOR}=1.27,95 \% \mathrm{CI}=1.20,1.35)$, youth with $\mathrm{BMI} \geq 30(\mathrm{AOR}=1.44,95 \% \mathrm{CI}=1.27,1.64)$, and youth who perceived they were overweight $(\mathrm{AOR}=2.25$, $95 \% \mathrm{CI}=1.89,2.66)$ all had significantly greater odds of being bullied at school compared with boys, youth with BMI $<30$, and youth who perceived themselves as not

Table 3. Sex- and Weight-based Disparities in Bullying and Cyberbullying: YRBS (2011)

\begin{tabular}{|lll|}
\hline & & \multicolumn{2}{c|}{ AOR (95\% Cl) } \\
\cline { 2 - 3 } Disparity group & Bullying & Cyberbullying \\
\hline $\begin{array}{l}\text { Sex } \\
\quad \text { Females vs. males }\end{array}$ & $1.27(1.20$ to 1.35$)$ & 2.34 (2.20 to 2.50) \\
BMI & $1.44(1.27$ to 1.64$)$ & 1.11 (0.97 to 1.27) \\
$\begin{array}{c}\text { BMI } \geq 30 \text { vs BMI }<30 \\
\text { Self-perceived weight } \\
\text { Very overweight versus not }\end{array}$ & $2.25(1.89$ to 2.66$)$ & 1.79 (1.49 to 2.14) \\
\hline
\end{tabular}

YRBS, Youth Risk Behavior Surveillance. 
Table 4. Relationship Between Anti-bullying Legislation and Sex- and Weight-based Bullying: YRBS (2011)

\begin{tabular}{|c|c|c|c|c|c|c|}
\hline \multirow{2}{*}{$\begin{array}{l}\text { Legislation variable } \\
\text { Comprehensive score }\end{array}$} & \multicolumn{3}{|c|}{ Bullying: AOR (95\% Cl) } & \multicolumn{3}{|c|}{ Bullying: ROR (95\% Cl) } \\
\hline & Low & Medium & High & Medium/Low & High/Low & High/Medium \\
\hline $\operatorname{Sex}^{\mathrm{a}}$ & 1.22 (1.13 to 1.30$)$ & 1.29 (1.18 to 1.41$)$ & 1.28 (1.15 to 1.44$)$ & 1.06 (0.95 to 1.19$)$ & $1.06(0.92$ to 1.21$)$ & 1.00 (0.86 to 1.15$)$ \\
\hline $\mathrm{BMI}^{\mathrm{b}}$ & 1.32 (1.04 to 1.67$)$ & 1.50 (1.23 to 1.84$)$ & 1.42 (1.24 to 1.63$)$ & 1.14 (0.84 to 1.55$)$ & 1.08 (0.82 to 1.42$)$ & 0.95 (0.75 to 1.20$)$ \\
\hline Self-perceived weight ${ }^{c}$ & 1.79 (1.42 to 2.25$)$ & 2.48 (2.00 to 3.09 ) & 2.07 (1.52 to 2.80$)$ & 1.39 (1.02 to 1.89$)$ & $1.16(0.79$ to 1.69$)$ & $0.83(0.57$ to 1.20$)$ \\
\hline Compliance with DOE enumeration ${ }^{d}$ & None & Partial & Full & Partial/None & Full/None & Full/Partial \\
\hline Sex & 1.31 (1.21 to 1.41$)$ & 1.43 (1.24 to 1.65$)$ & 1.18 (1.05 to 1.32$)$ & $1.10(0.93$ to 1.29$)$ & 0.90 (0.79 to 1.04$)$ & $0.82(0.68$ to 0.99$)$ \\
\hline BMI & 1.33 (1.14 to 1.55$)$ & 1.38 (0.94 to 2.04$)$ & 1.71 (1.41 to 2.08 ) & 1.04 (0.69 to 1.58 ) & 1.29 (1.01 to 1.65$)$ & 1.24 (0.80 to 1.90$)$ \\
\hline Self-perceived weight & 2.06 (1.83 to 2.32 ) & 1.90 (1.06 to 3.40$)$ & 2.86 (2.00 to 4.10$)$ & 0.92 (0.51 to 1.67$)$ & 1.39 (0.96 to 2.02$)$ & 1.51 (0.76 to 2.97$)$ \\
\hline Specific enumeration & Enumerated & Not enumerated & & Enumerated/Not & & \\
\hline Sex & 1.22 (1.11 to 1.34$)$ & 1.31 (1.21 to 1.41$)$ & & 0.94 (0.83 to 1.06$)$ & & \\
\hline BMI & 1.40 (1.17 to 1.66$)$ & 1.45 (1.25 to 1.69$)$ & & 0.96 (0.77 to 1.20$)$ & & \\
\hline \multirow[t]{2}{*}{ Self-perceived weight } & 2.19 (1.56 to 3.08$)$ & 2.26 (1.86 to 2.75 ) & & 0.97 (0.66 to 1.43$)$ & & \\
\hline & \multicolumn{3}{|c|}{ Cyberbullying: AOR (95\% CI) } & \multicolumn{3}{|c|}{ Cyberbullying: ROR (95\% Cl) } \\
\hline Comprehensive score & Low & Medium & High & Medium/Low & High/Low & High/Medium \\
\hline Sex & 2.08 (1.95 to 2.23 ) & 2.47 (2.23 to 2.73 ) & 2.31 (2.05 to 2.60$)$ & 1.18 (1.05 to 1.34$)$ & 1.11 (0.97 to 1.27$)$ & 0.94 (0.80 to 1.10$)$ \\
\hline BMI & 1.13 (0.88 to 1.43$)$ & 1.15 (0.93 to 1.41$)$ & 1.02 (0.86 to 1.22$)$ & 1.02 (0.75 to 1.39$)$ & 0.91 (0.68 to 1.22$)$ & 0.89 (0.69 to 1.16$)$ \\
\hline Self-perceived weight & 1.84 (1.39 to 2.42$)$ & 1.82 (1.38 to 2.41 ) & 1.70 (1.35 to 2.14$)$ & 0.99 (0.67 to 1.47$)$ & 0.93 (0.64 to 1.33$)$ & 0.93 (0.65 to 1.34$)$ \\
\hline Compliance with DOE enumeration & None & Partial & Full & Partial/None & Full/None & Full/Partial \\
\hline Sex & 2.35 (2.14 to 2.57$)$ & 2.63 (2.36 to 2.93 ) & 2.26 (2.03 to 2.52 ) & 1.12 (0.97 to 1.29$)$ & $0.96(0.84$ to 1.11$)$ & 0.86 (0.74 to 1.00$)$ \\
\hline BMI & $1.10(0.91$ to 1.32$)$ & 1.10 (0.96 to 1.26$)$ & 1.14 (0.90 to 1.43 ) & 1.00 (0.8 to 1.25$)$ & $1.03(0.77$ to 1.38$)$ & 1.03 (0.79 to 1.35$)$ \\
\hline Self-perceived weight & 1.73 (1.34 to 2.24 ) & 1.82 (1.24 to 2.67$)$ & 1.91 (1.47 to 2.49 ) & 1.05 (0.66 to 1.68$)$ & 1.11 (0.77 to 1.58$)$ & 1.05 (0.66 to 1.67 ) \\
\hline Specific enumeration & Enumerated & Not enumerated & & Enumerated/Not & & \\
\hline Sex & 2.33 (2.14 to 2.54 ) & 2.35 (2.14 to 2.57$)$ & & 0.99 (0.88 to 1.13$)$ & & \\
\hline BMI & $1.00(0.77$ to 1.28$)$ & 1.14 (0.98 to 1.33 ) & & 0.88 (0.65 to 1.17$)$ & & \\
\hline Self-perceived weight & 1.73 (1.36 to 2.20$)$ & 1.80 (1.45 to 2.23 ) & & 0.96 (0.70 to 1.32$)$ & & \\
\hline
\end{tabular}

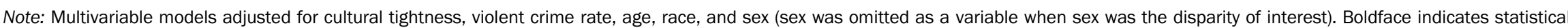

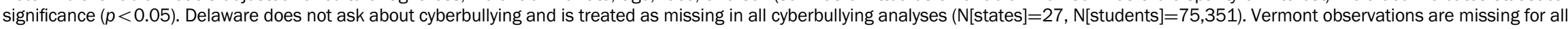

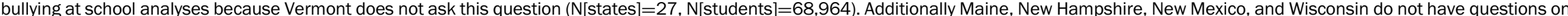

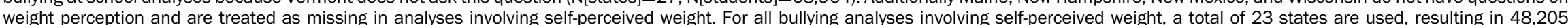
observations. For the equivalent analyses in cyberbullying, 23 states were used, resulting in 54,408 observations. All 28 states reported student BMI and sex.

${ }^{a}$ Females vs males.

${ }^{\mathrm{b}} \mathrm{BMI} \geq 30$ vs $\mathrm{BMI}<30$.

Very Overweight vs Not.

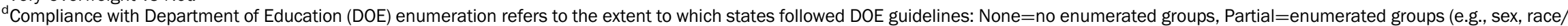
ethnicity) with limited coverage to those groups, Full=enumerated groups with coverage not limited to those groups.

ROR, ratio of AORs; YRBS, Youth Risk Behavior Surveillance. 
significantly overweight, respectively. Similar disparities were also observed for cyberbullying (Table 3).

Table 4 reports the AORs for bullying and cyberbullying comparing sex, BMI, and perceived weight by levels of compliance to DOE guidelines for three specific categories: overall compliance to all DOE components, compliance to DOE enumeration of groups, and enumeration of specific groups. Bullying disparities by sex $(\mathrm{ROR}=1.06,95 \% \mathrm{CI}=0.92,1.21), \mathrm{BMI}(\mathrm{ROR}=1.08,95 \%$ $\mathrm{CI}=0.82,1.42)$, and perceived weight $(\mathrm{ROR}=1.16,95 \%$ $\mathrm{CI}=0.79,1.69)$ were not significantly different in states with low versus high compliance to all DOE components. Cyberbullying disparities did not improve with increased compliance to DOE guidelines.

Increased compliance specifically to DOE enumeration guidelines was also not associated with lower BMI or perceived weight disparities. However, sex disparities in bullying were significantly lower in states with high compliance to enumeration guidelines (full versus partial compliance: $\mathrm{ROR}=0.82,95 \% \mathrm{CI}=0.68,0.99$ ).

Finally, specific enumeration of sex or physical appearance/attributes/weight in anti-bullying laws was not associated with lower levels of weight- or sex-based disparities in bullying or cyberbullying.

\section{DISCUSSION}

Epidemiologic evidence has consistently shown that certain groups of youth are at disproportionate risk of being bullied by their peers. ${ }^{2,20,21}$ Emerging research suggests that anti-bullying legislation may be one structural lever for reducing rates of bullying. ${ }^{8,9}$ However, this research has not yet documented whether anti-bullying legislation is effective at addressing disparities in bullying outcomes, a topic that was specifically identified as an important direction for future research in the recent National Academy of Sciences report on bullying. ${ }^{7}$ The current study begins to address this gap in the literature. This study, which used data from a comprehensive content analysis of state anti-bullying legislation linked to a data set of 79,577 youth, examined the relationship between several aspects of anti-bullying legislationincluding overall comprehensiveness and enumeration of specific groups-and bullying disparities related to weight and sex.

Neither comprehensiveness nor enumeration of specific groups was associated with lower weight-based disparities in bullying and cyberbullying (and in two cases, more-comprehensive policies and greater compliance with DOE enumeration were associated with significantly wider weight-based disparities in bullying). The lack of specificity with respect to weight in the law may explain these findings; indeed, only one state specifically enumerated weight (versus physical appearance/attributes). Given that physical appearance/attributes include characteristics other than weight, this broad category in policies may be insufficient to address weightbased bullying, a hypothesis requiring further testing.

Modest evidence suggests that high compliance with DOE enumeration guidelines was associated with lower sex differences in bullying. However, more-comprehensive laws were associated with higher sex disparities in cyberbullying, and specific enumeration of sex was not associated with lower sex differences in bullying and cyberbullying. These mixed findings suggest that laws still need to be strengthened with guidelines specific to non-dominant, targeted groups. This idea is consistent with the literature on legal critiques of race- and sex-"blind" approaches, ${ }^{22,23}$ which tend to reinforce the status quo or widen current disparities, because they are designed around the experiences of the dominant group (e.g., men) and therefore neglect to address the unique ways in which the non-dominant group (e.g., women) are affected by some prohibited behavior.

Together, these data suggest that anti-bullying legislation needs to be enhanced to reduce the large disparities in bullying. Identifying new components of anti-bullying laws that can be added to existing legislation is particularly needed. Fortunately, the literature already provides some potential areas for improvement. Specifically, stigma and prejudice are common underlying factors across most groups at disproportionate risk of bullying, yet none of the 16 key components of the DOE framework (with the exception of enumerated groups) focuses on these underlying motivations for bullying. It may be, for instance, that anti-bullying policies should require interventions that explicitly address bias-based bullying, ${ }^{24}$ but this awaits empirical testing. Additional research is also needed to identify the factors that render the enumeration of groups more or less effective in reducing bullying disparities. For instance, in states whose laws enumerate protected groups, how is the school climate related to tolerance and diversity modified or enhanced to reduce disparities in bullying?

\section{Limitations}

This study has several limitations. First, these data are crosssectional. Consequently, it is not possible to establish causal relationships between anti-bullying policies and disparities in bullying. Longitudinal research is necessary to examine whether disparities in bullying are reduced following the implementation of comprehensive anti-bullying policies that include enumerations. Second, YRBSS includes a measure of sex but not of gender expression or identity; thus, it is unknown whether similar results would be observed for gender-nonconforming students. Third, these results are generalizable only to the 28 states that were 
included in the study and to high school students. Future research is needed to expand to all U.S. states and to middle school youth. Fourth, the policy data were coded in 2011. Because anti-bullying legislation has changed since then, future studies should examine whether the results hold with current legislation. Finally, this study used one anti-bullying framework for coding legislation (DOE); the extent to which these results are generalizable to other frameworks, such as the anti-bullying public health framework, ${ }^{25}$ remains to be determined.

Strengths of the study include the use of a large, geographically diverse, population-based sample of youth. The categorization of state policies was completed through expert consensus by the DOE. This methodologic approach overcomes same-source bias, ${ }^{26}$ which can introduce spurious results when the exposure and outcome variables are measured via the same method. Because the policy measures were linked to individuallevel measures of bullying and cyberbullying, the study should not be subject to the ecologic fallacy, which can occur when inferences about the effect of ecologic influences rely on aggregated reports of the outcome. ${ }^{27}$

\section{CONCLUSIONS}

Though some policies hold promise in addressing social inequalities, existing research has rarely determined the extent to which anti-bullying legislation is effective in ameliorating disparities in bullying. The present study provides initial evidence that current legislation does not reduce weight-based disparities, and is only minimally effective in reducing sex-based disparities, in bullying and cyberbullying among high school students in the U.S. This research suggests that existing policies need to be augmented to protect youth who are most vulnerable to bullying. Such efforts will require sustained collaborations among social scientists, public health professionals, school personnel, parents, and policymakers to initiate ongoing evaluation efforts needed to create evidencebased policies capable of eliminating disparities in bullying.

\section{ACKNOWLEDGMENTS}

No financial disclosures were reported by the authors of this paper.

\section{REFERENCES}

1. Kann L, Kinchen S, Shanklin SL, et al. Youth risk behavior surveillance -United States, 2013. MMWR Surveill Summ. 2014;63(4):1-168.

2. Puhl RM, Latner JD. Stigma, obesity, and the health of the nation's children. Psychol Bull. 2007;133(4):557-580. https://doi.org/10.1037/ 0033-2909.133.4.557.
3. Gray WN, Kahhan NA, Janicke DM. Peer victimization and pediatric obesity: a review of the literature. Psychol Sch. 2009;46(8):720-727. https://doi.org/10.1002/pits.20410.

4. Ogden CL, Carroll MD, Kit BK, Flegal KM. Prevalence of childhood and adult obesity in the United States, 2011-2012. JAMA. 2014;311 (8):806-814. https://doi.org/10.1001/jama.2014.732.

5. Student reports of bullying and cyberbullying: results from the 2013 School Crime Supplement to the National Crime Victimization Survey. U.S. Department of Education, April 2015, NCES 2015-056. https:// nces.ed.gov/pubs2015/2015056.pdf.

6. Arseneault L, Bowes L, Shakoor S. Bullying victimization in youths and mental health problems: 'Much ado about nothing'? Psychol Med. 2010;40(5):717-729. https://doi.org/10.1017/S0033291709991383.

7. National Academy of Sciences. Preventing Bullying through Science, Policy, and Practice. Washington, DC: The National Academies Press; 2016.

8. Hatzenbuehler ML, Schwab-Reese L, Ranapurwala SI, Hertz MF, Ramirez MR. Associations between antibullying policies and bullying in 25 states. JAMA Pediatr. 2015;169(10):e152411. https://doi.org/ 10.1001/jamapediatrics.2015.2411.

9. Ramirez MR, Ten Eyck P, Onwuachi-Willig A, Peek-Asa C, Cavanaugh J. Evaluation of Iowa's anti-bullying law. Inj Epidemiol. 2016; 3(1):15. https://doi.org/10.1186/s40621-016-0080-9.

10. Hatzenbuehler ML, Keyes KM, Hasin DS. State-level policies and psychiatric morbidity in lesbian, gay, and bisexual populations. Am J Public Health. 2009;99(12):2275-2281. https://doi.org/10.2105/AJPH. 2008.153510.

11. Hatzenbuehler ML, O’Cleirigh C, Grasso C, Mayer K, Safren S, Bradford J. Effect of same-sex marriage laws on health care use and expenditures in sexual minority men: a quasi-natural experiment. $A m \mathrm{~J}$ Public Health. 2012;102(2):285-291. https://doi.org/10.2105/AJPH. 2011.300382.

12. Krieger N, Chen JT, Coull B, Waterman PD, Beckfield J. The unique impact of abolition of Jim Crow laws on reducing inequities in infant death rates and implications for choice of comparison groups in analyzing societal determinants of health. Am J Public Health. 2013;103 (12):2234-2244. https://doi.org/10.2105/AJPH.2013.301350.

13. Rubin MS, Colen CG, Link BG. Examination of inequalities in HIV/ AIDS mortality in the United States from a fundamental cause perspective. Am J Public Health. 2010;100(6):1053-1059. https://doi. org/10.2105/AJPH.2009.170241.

14. CDC. Youth Risk Behavior Surveillance System (YRBSS). 2015. www cdc.gov/healthyyouth/data/yrbs/index.htm Accessed May 31, 2016.

15. Stuart-Cassel V, Bell A, Springer F. Analysis of state bullying laws and policies. Washington, DC: U.S. Department of Education; 2011. www2. ed.gov/rschstat/eval/bullying/state-bullying-laws/state-bullying-laws. pdf.

16. Major B, Hunger JM, Bunyan DP, Miller CT. The ironic effects of weight stigma. J Exp Soc Psychol. 2014;51:74-80. https://doi.org/ 10.1016/j.jesp.2013.11.009.

17. U.S. Department of Justice. Uniform Crime Reporting Statistics. 2010. www.ucrdatatool.gov/Search/Crime/Crime.cfm. Accessed July 3, 2015.

18. Harrington JR, Gelfand MJ. Tightness-looseness across the 50 united states. Proc Natl Acad Sci U S A. 2014;111(22):7990-7995. https://doi. org/10.1073/pnas.1317937111.

19. Greenland S, Pearl J, Robins JM. Causal diagrams for epidemiologic research. Epidemiology. 1999;10(1):37-48. https://doi.org/10.1097/ 00001648-199901000-00008.

20. Olsen EOM, Kann L, Vivolo-Kantor A, Kinchen S, McManus T. School violence and bullying among sexual minority high school students, 2009-2011. J Adolesc Health. 2014;55(3):432-438. https://doi.org/ 10.1016/j.jadohealth.2014.03.002.

21. Rose CA, Stormont M, Wang Z, Simpson CG, Preast JL, Green AL. Bullying and students with disabilities: examination of disability status 
and educational placement. School Psych Rev. 2015;44(4):425. https: //doi.org/10.17105/spr-15-0080.1.

22. Peery D. The colorblind ideal in a race-conscious reality: the case for a new legal ideal for race relations. Northwest J Law Soc Policy. 2011; 6(w):473.

23. Clarke JA. Beyond equality? Against the universal turn in workplace protections. Ind Law J. 2011;86(4):1219.

24. Russell ST, Sinclair KO, Poteat VP, Koenig BW. Adolescent health and harassment based on discriminatory bias. Am J Public Health. 2012;102(3):493-495. https://doi.org/10.2105/AJPH.2011.300430.
25. Srabstein JC, Berkman BE, Pyntikova E. Anti-bullying legislation: a public health perspective. J Adolesc Health. 2008;42(1):11-20. https: //doi.org/10.1016/j.jadohealth.2007.10.007.

26. Diez Roux AV. Neighborhoods and health: where are we and where do we go from here? Rev Epidemiol Sante Publique. 2007;55(1):13-21. https://doi.org/10.1016/j.respe.2006.12.003.

27. Schwartz S. The fallacy of the ecological fallacy: the potential misuse of a concept and the consequences. Am J Public Health. 1994;84(5): 819-824. https://doi.org/10.2105/AJPH.84.5.819. 